\title{
LA PERPETUA REINVENCIÓN DE LA IDENTIDAD DE LOS GÉNEROS EN EL BAILE FLAMENCO.
}

\section{The perpetual genders identity re-invention in flamenco dance.}

\author{
Eva OrdóÑEz Flores \\ Doctor de la Universidad de la Sorbona. 8, rue Alfred Durand Claye 75014 París. \\ Francia. Teléfono: +33 (0)1 404440 83. Móvil: +33 (0)6 58105276. \\ eva.ordonez@wanadoo.fr
}

Recibido: 19 de Junio de 2010

Aprobado: 5 de Julio de 2010

\begin{abstract}
Resumen:
En el presente estudio sobre le baile famenco, se pone en evidencia de qué manera la cuestión del género representa un tema recurrente y un verdadero reto en términos de creatividad. El famenco se encuentra en una búsqueda perpetua del equilibrio entre lo tradicional y lo contemporáneo. Las circunstancias en las cuales se le vio nacer, hacen que esta búsqueda y esta constante mutación, formen parte de su esencia. Cuando en un espectáculo de danza la representación de los papeles del hombre y de la mujer se ven modif cados con respecto a la idea de "lo tradicional", es legítimo plantearse interrogantes existenciales. El baile f amenco, al igual que todas la otras formas de danza contemporáneas, re f eja su entorno, contribuye a su innovación e interactúa con ella. Es un acto social.
\end{abstract}

Palabras clave: danza, f amenco, género, identidad.

Ordóñez Flores, E. 2011: La perpetua reinvención de la identidad de géneros en el bailef amenco. Arte, Individuo y Sociedad, 23 (1), 19-28.

\begin{abstract}
Abstrac:
In the case of this study about $\mathrm{f}$ amenco dance, it is spotlighted how the matter of genders is a recurrent topic and a challenge in terms of creativity . Flamenco is in a perpetual search of a balance between tradition and contemporarily. Circumstance in which it was born, make this search and this constant mutation as part of its essence. When in a performance the representation of man and woman parts are modif ed according to the "traditional idea", it brings up existential questions. Flamenco dance, like all the other contemporary forms of dance, re f ects its context, contributes to its innovation and interacts with it. It is a social act.
\end{abstract}

Key words: dance, f amenco, gender, identity.

Sumario: Introducción, 1. Proporciones de la población masculina y femenina en el mundo famenco, 2. El traje, 3. Los palos f amencos. 4. El tratamiento de las estructuras coreográ f cas, 5. Las plásticas masculina y femenina, 5.1 El espacio escénico, la coreografía de líneas y los niveles corporales, 5.2 El cuerpo en movimiento, Conclusiones. Referencias bibliográf cas. 


\section{Introducción}

La segunda Revolución Industrial ${ }^{1}$ sirve de tela de fondo a la cristalización del famenco $^{2}$. Este contexto sociohistórico no parece ajeno a su idiosincrasia y a su forma actual (Rice: 2003). Este periodo histórico conlleva una gran cantidad de cambios sociales que va a darle alf amenco una parte de su signif cado, de su razón de ser y de su esencia, es decir, de su estética. La historia pasa aquí a una velocidad superior donde todo se acelera, y la sociedad contemporánea, donde elf amenco permanece vivo, es un producto de esta Revolución. Esta con f guración, le ha conferido al famenco una gran capacidad de adaptación y de supervivencia en este contexto en constante movimiento.

Entre otros aspectos, cabe destacar la mutación del papel de la mujer en las sociedades occidentales durante esta revolución. Masivamente, comienza a competir con el hombre en el mercado laboral. Esto le conf ere un valor mercantil que no tenía antes. Progresivamente, su lugar en la sociedad cambia, adquiere un poder adquisitivo y su relación con el hombre cambia también. La mujer parte a la conquista de la igualdad. Esto se percibe a primera vista al adoptar prendas masculinas. Se asiste a un fenómeno de transición de una sociedad tradicional hacia una sociedad moderna y es lo que se percibe en la diferenciación identitaria entre el hombre y la mujer que se opera al paso del tiempo. Una diferenciación evidente pero cambiante, creando sin cesar nuevos modos y nuevas formas distintivas.

$\mathrm{El} \mathrm{f}$ amenco no es un folklore que las poblaciones practican reproduciendo una y otra vez un modelof jo y fosilizado cuya forma no se modf ca casi nada y no se tiene particular interés a que se modi f que. Supera la dimensión folklórica para adaptarse a su tiempo caracterizado por un movimiento perpetuo a una velocidad hasta ahora jamás alcanzada. De este modo, permanece vivo (Guilcher: 1988). Es permeable a su contexto y el contexto se re f eja en él. Por consiguiente, el sistema actual, ya sea social, económico, industrial, político... de un modo o de otro, quedan plasmados en esta expresión artística.

Este estudio mostrará concretamente cómo la tendencia actual a la igualdad de géneros y otros cambios conceptuales relativos a la identidad sexual, se ven re f ejados en los actores del baile f amenco y sus producciones artísticas.

\section{Proporciones de la población masculina y femenina en el mundo flamenco}

Resulta importante situar el baile con respecto a las demás disciplinas vinculadas al famenco. Eso permite ubicar a la danza en su contexto y re fexionar sobre la percepción y la idea que la población a f cionada y/o profesional se hace en realidad y cómo se percibe dentro incluso de su propia comunidad. La relación entre la población masculina y femenina varía en función de la disciplina practicada. Cuando se observa el paisaje de la guitarra famenca está ocupado casi exclusivamente por el género maculino. Si se observa más concretamente la escena internacional, no existe mujer guitarrista de $\mathrm{f}$ amenco de fama mundial ni incluso nacional. A nuestro conocimiento, no hay ninguna mujer guitarrista de reputación hoy día y, aunque eso tampoco haya sido el caso antaño, siempre ha sido poco representada. Los máximos representantes son hombres: Paco Lucía, Tomatito, Vicente Amigo... 
En lo que se ref ere al cante, la distribución es más sutil pero no menos reveladora. Para bosquejar rápidamente el fenómeno actual se podría decir que, generalmente, los hombres tienen la hegemonía del cante hondo, serio, difícil, profundo... y se relega a las mujeres al cante chico y festivo, aunque exista ninguna obligación implícita en este sentido. Esto no ha sido siempre el caso. Antaño, existían f guras femeninas representativas y respetadas como La Niña de los Peines, pero las circunstancias no eran las mismas. En efecto, no se exigía a los cantaores ${ }^{3}$ el tener los conocimientos enciclopédicos que se les exige hoy en día para ser reconocidos. Este hecho pone de manif esto que la competición por llegar a resultados no está solamente vinculada a la clásica industria de producción sino también a las empresas artísticas que se han convertido a su vez en máquinas de producción. Sin embar go, actualmente hay cantaoras famosas y reconocidas, como es el caso de Carmen Linares, que son capaces de interpretar cualquier parte del extenso repertorio f amenco. A pesar de todo, la mujer sigue poco representada en el cante.

Con respecto al baile cabe señalar que la interpretación y la creación están estrechamente vinculadas: el bailaor ${ }^{4}$ es también coreógrafo, o al menos ha de ser capaz de crear sus propias coreografías. Por lo tanto, un coreógrafo de balletf amenco es, o fue, él mismo bailarín ${ }^{5}$. Es debido a esto que se distinguirá por una parte al bailarín, sobrentendiendo bailarín-coreógrafo, y por otra parte al coreógrafo, sobrentendiendo coreógrafo de ballet. De manera análoga a casi todo el mundo occidental, hay bastante más bailaoras que bailaores. Es a partir de este momento en que la interpretación de este estado de hecho se complica ya que, si las bailarinas y bailaoras reconocidas son más numerosas que los bailarines y bailaores reconocidos, aunque se tienda a la igualdad, las cosas se invierten cuando se trata de la función de coreógrafo. No sólo los hombres son más numerosos sino que su reconocimiento público es mayor . Sin embargo, esto también tiende a equilibrarse.

\section{El traje}

A pesar de que, de manera general, el atuendo masculino y femenino sean muy diferentes entre ellos, se pueden observar en fotografías de principios del siglo XIX (Fernando el de Triana: 1935) a mujeres ataviadas con traje de chaquetilla corta y pantalón, traje propio del hombre, sin dejar de perder su atractivo femenino. Hoy en día, las bailaoras y bailarinas siguen llevándo este tipo de atuendo.

Los accesorios constituyen una parte importante en el baile $\mathrm{f}$ amenco. Si a principios del siglo XIX bailaores y bailaoras los utilizaban, hoy en día, el sombrero cordobés propio del garrotín ha desaparecido casi por completo del atuendo masculino. Los accesorios como el mantón, el pericón y el sombrero cordobés, este último en menor grado, siguen siendo utilizados por la bailaora.

Que sea masculina o femenina, la vestimenta del baile famenco sigue las variaciones vinculadas a la moda de la vida cotidiana que hace cien años era muy diferente a le de hoy. El traje del bailaor sigue la moda vestimentaria urbana. Hay ballets que utilizan trajes tradicionales de antaño, con chaqueta corta, chalecos bordados, pantalón de talle alto... a la vez que utilizan, a veces hasta en la misma obra, trajes urbanos contemporáneos. En cuanto a la mujer, su vestimenta se ha aligerado extremadamen- 
te permitiendo entre otras cosas una mayor libertad de movimiento. Los trajes que antes se caracterizaban por una gran cantidad de volantes, tienden hoy a desaparecer permitiendo así una f gura corporal de mayor sobriedad. Algunos ballets mezclan varios estilos haciendo así un guiño de ojo nostálgico al pasado. De este modo, los estilos indumentarios se superponen, de manera más frecuente en el hombre.

Sin embargo, la moda no es el único fenómeno de sociedad que se re f eja en la vestimenta. Las creaciones más rebeldes ante las normas tradicionales de estos aspectos a los cuales se ha podido asistir hasta hoy han sido "El rango" de RafaelAguilar en 1979, "Pasión Gitana" de Joaquín Cortés en 1995 y "La Casa de Bernarda Alba" de Antonio Canales en 1998.

En "El rango", creación inspirada de "La casa de BernardaAlba", Antonio Gades, bailarín principal, desempeña el papel de la madre castradora y autoritaria que impone a sus cuatro jóvenes hijas un luto severo por la muerte del padre. Rafael Aguilar, asigna así las características masculinas de nuestra sociedad occidental, autoridad y severidad, a un personaje femenino que se presupone debe de ser dulce y maternal.

En Pasión gitana, Joaquín Cortés juega y trans f ere al bailaor elementos tradicionalmente femeninos y a la bailaora elementos tradicionalmente masculinos. El mismo Joaquín Cortés, baila sin camisa y con una amplia falda. Por otro lado, hace bailar a un bailarín clásico, también sin camisa, con una falda de cola. En uno de los bailes de esta obra, las bailarinas visten con chaleco y pantalón. Por medio de esta androgeneidad, Joaquín Cortés rompe el esquema extremadamente sexuado del baile famenco. Los comportamientos puestos aquí en escena, traducen interrogaciones contemporáneas en cuanto al papel del hombre y la mujer en la sociedad.

A través de estas creaciones, los coreógrafos ponen en tela de juicio lo que serían los principios básicos del f amenco. En La Casa de Bernarda Alba, obra teatral cuyos personajes son todos femeninos, es íntegramente interpretada por bailarines hombres. Un fenómeno como el travestimiento puede parecer curioso, pero f nalmente no es más asombroso vista la permeabilidad del $\mathrm{f}$ amenco. El hecho de que Antonio Canales coreograf ara La casa de Bernarda Alba para cinco bailarines mientras que los personajes de la obra son femeninos, revela probablemente un fenómeno de coming out "artístico" por parte del coreógrafo.

Estas creaciones no hacen más que ref ejar las cuestionamientos y los cambios de una sociedad de una manera muy directa (Hanna: 1987).

\section{Los palos ${ }^{6}$ flamencos}

La mayoría de los palos famencos, más de treinta, pueden ser bailados por ambos géneros. Existen sin embargo algunas excepciones como la farruca ${ }^{7}$, que por ser un baile por de f nición viril, se considera como un baile de hombre. Por otro lado, los caracoles $^{8}$, que aunque no haya una real prohibición explícita hay una prescripción tácita, se consideran un baile de mujer probablemente porque lo propio de este baile es el pericón ${ }^{9}$ en primer lugar y la bata de cola en segundo lugar. Cuando este baile se presenta en forma de ballet, puede haber tanto hombres como mujeres ya que la "las marcas indumentarias" de los caracoles aparecen. Por su lado, Gades opone en su "Suite f amenca" de 1963 un número en el que alterna un baile de zapateado ${ }^{10}$ 
interpretado por hombres y un tanguillo interpretado por mujeres. La oposición se realiza en el tipo de percusión empleada: zapateado ${ }^{11}$ por los hombres y castañuelas por las mujeres. Por otro lado, se podría efectuar una oposición entre el martinete 12 masculino y la seguiriya ${ }^{13}$ femenina. Hasta hace poco, se podía considerar al martinete como un baile de hombre por ser su creador Antonio El Bailarín, un hombre, y por que su principal rasgo coreográf co es el de un zapateado ${ }^{14}$ casi permanente para contrarrestar el apoyo rítmico ya que el cante carece de acompañamiento a la guitarra. Sin embargo, desde $\mathrm{f}$ nales de los años 80 , algunas bailaoras inician un baile por seguiriyas con un martinete.

Por lo general, la mayoría de los palos de compás binario, a excepción de la farruca, son más bien femeninos en términos de baile, pero esto no impide ningún bailaor de interpretarlos.

Todas estas observaciones son de orden general. Lo que a principios del siglo veinte aparecía como una evidencia, lo es menos hoy en día. Aunque Sara Baras en su creación "Sensaciones" de 1998 baile una farruca y la elección de este palo para su interpretación no incomode ni sorprenda a nadie, no deja de considerarse como original.

\section{El tratamiento de las estructuras coreográficas}

Las coreografías del baile famenco, presentadas en su tradicional forma de cuadro f amenco ${ }^{15}$, siguen une estructura preestablecida. Cada elemento estructural es variable y relativamente libre (Ordóñez Flores: 2008). De una manera general, las coreografías se componen de la siguiente manera:

1. Entrada del cante

2. Letra

3. Escobilla 16

4. Final 17

Hasta los años 70, el bailaor le daba más importancia a la parte estructural de la escobilla. Para un mismo palo, estas partes eran de mayor duración en el baile del hombre que en el de la mujer de manera evidente (Ordóñez Flores: 2001).

Si se observan y analizan imágenes de bailes grabados a principios del siglo XX, se percata uno que los hombres y las mujeres no trataban de la misma manera los elementos estructurales del baile que interpretaban. A los bailaores se les apreciaba por sus zapateados en f ligranas y a las bailaoras por su gracia y su simpatía. Las « mejores » de ellas recibían en calif cativo de bailaoras punteras (Fernando el de Triana: 1935) porque efectuaban pasos ligeros y silenciosos.

Carmen Amaya ${ }^{18}$ rompe de f nitivamente con este canon estético y , cerca de 20 años después de su muerte, a partir de los años 80 , el zapateado se generaliza el en baile de mujer, tomando un lugar tan importante que la bailaora abandona todo aquello que caracteriza a la feminidad famenca, es decir la sonrisa, la gracia y la sensualidad. 
Por regla general, actualmente el uso del zapateado tiende a uniformizarse. Las escobillas van tomando mayor importancia tanto en términos cuantitativos como cualitativos. Es decir que se aporta un especial esmero a la innovación musical de estas. Las coreografías masculinas tienen tendencia a saltarse los silencios ${ }^{19}$ en los bailes por alegrías ${ }^{20}$. Por esta razón, el bailaor soluciona el problema interpretando otro palo próximo a la alegría que no contenga silencio, como pueden ser el mirabrás ${ }^{21}$ y la romera $^{22}$. La otra solución para evitar un silencio es el de componer el baile con coplas de diferentes palos, siempre de la misma familia que la alegría, ya que de este modo no se puede realmente identif car el baile con un palo en concreto.

Por otro lado, los bailes que llevan lar gas partes estructurales muy lentas, como la caña $a^{23}$ y los caracoles, obligan a muchos desplazamientos y braceos. Una escobilla larga, prolongaría demasiado el baile. Quedando poco lugar para escobillas, estos palos no suelen ser bailados por hombres.

Se ha visto aquí que a pesar de que no haya realmente bailes reservados a hombres o a mujeres, cada uno elige sus preferencias.

La tendencia actual en el baile de mujer , es la de equilibrar las características tradicionalmente atribuidas a la mujer con aquellas atribuidas al hombre. Algunas bailaoras como Milagros Mengíbar, experimentan un movimiento de vuelta a la tradición reinterpretando una llamada ${ }^{24}$ marcada simplemente con un gesto sugestivo en vez de af rmarse con la habitual combinación de zapateado que supone la llamada. Asimismo, Sara Baras, sin dejar de lado su prodigiosa técnica introduce gestos y pasos propios del baile de mujer como lo son las vueltas quebradas hoy en día en desuso.

\section{Las plásticas masculina y femenina}

\subsection{El espacio escénico, la coreografía de líneas y los niveles corporales}

Siendo las escobillas elementos coreográ $f$ cos bastante estáticos, los bailes que contienen mucho zapateado, tendrán reducidas las capacidades de ocupación del espacio. A consecuencia de esto, los bailes interpretados por mujeres ocupaban más el espacio escénico que aquellos interpretados por hombres. Durante el período en el que la mujer accedió de manera masiva a la técnica del zapateado, los bailes se vieron reducidos en términos de ocupación del espacio. Sin embargo, la innovación del zapateado en estos últimos años permite mayores desplazamientos. En resumidas cuentas, hoy en día hombres y mujeres, tienden a ocupar ampliamente el espacio escénico.

La mujer mantiene una utilización de los niveles corporales más desarrollada que el hombre. El vestido oculta la posición de las piernas, permite f guras que resultarían inestéticas al llevar pantalones. El vestido le permite explorar muchos niveles, estirándose, pero también acurrucándose y recogiéndose. Estos movimientos están aún completamente inexplorados por el hombre, a no ser que los utilice de manera burlesca.

La utilización de los segmentos corporales resulta ser diferente en el baile del hombre y en el de la mujer. La simbólica de las caderas de la mujer está ligada a la fecundidad y por consiguiente a la sexualidad. En el baile famenco esta parte del 
cuerpo será ampliamente solicitada por la mujer contrariamente al hombre que mantendrá una postura fálica por oposición. El movimiento de las caderas acarrea kinesiológicamente por una acción en cadena, el movimiento de todos los miembros que se encuentran por encima suya. Son característicos de los bailes de mujer los movimientos de hombros, tórax y cintura, de pequeña o gran envegadura, secos o suaves.

Los movimientos de tórax y hombros son también característicos del baile de hombre, pero se limitan a movimientos rápidos, secos y de poca amplitud. El baile del hombre pone en valor su virilidad, su sentido del humor y su agilidad. En palos como la bulería ${ }^{25}$ es frecuente realizar pasos que simulan el comienzo de una caída hacia atrás o hacia los lados, apoyándose el bailarín sobre la parte externa de los tobillos y recuperando la verticalidad. Hoy en día, este tipo de paso ha entrado a formar parte del repertorio femenino.

\subsection{El cuerpo en movimiento}

En primer lugar, existen elementos comunes a ambos géneros que no han variado o han variado poco. La posición general, los movimientos de cabeza, la movilidad del talle y la movilidad de la caderas permanecen sin cambios.

En segundo lugar, algunos elementos masculinos han sido adoptados por las mujeres. Es muy frecuente encontrar movimientos de muñeca con los puños cerrados y, en menor proporción, movimientos de brazos bruscos. La expresión seria de la cara, más propria del hombre, se volvió casi una norma en la mujer entre los años 80 y 90 . De nuevo, desde hace unos diez años, las expresiones sonrientes y pícaras vuelven a aparecer en la mujer. Los movimientos de hombros suaves y de temblor, han desaparecido casi totalmente del baile de la mujer, sólo se han quedado aquellos secos. Las piruetas de tipo clásico comienzan a hacer su aparición en el baile de mujer en los años 80 . La proporción de las escobillas en cuanto a extensión y cantidad ha llegado a igualarse entre el baile de hombre y el de la mujer.

En tercer lugar, algunos elementos propiamente femeninos se han visto adoptados en el baile del hombre. Guardando toda proporción, los movimientos de mano con los dedos desligados, entran más frecuentemente a formar parte de los elementos de interpretación masculina. Al igual que la mujer, el movimiento de muñecas y brazos toman amplitud. A principios del siglo XIX casi no existían movimientos de brazos en los hombres limitándose la mayoría de las veces a sujetarse la chaquetilla o el chaleco.

En cuarto lugar, determinados elementos propios al baile $\mathrm{f}$ amenco tienden a desaparecer. Es el caso de los movimientos secos de hombros y tórax en el hombre y de los movimientos de hombros temblados, redondos y suaves en la mujer. Asimismo, tiende a desaparecer la típica vuelta $\mathrm{f}$ amenca ${ }^{26}$ común a ambos géneros.

En quinto lugar, cada género por su lado busca nuevos elementos diferenciadores. Así es como el bailaor cultiva la pirueta clásica buscando un máximo de vueltas. Esta hazaña técnica, exigiendo un perfecto sentido del equilibrio que se obtiene por la verticalidad de su posición durante el transcurso de la pirueta, responde punto por punto al símbolo fálico. 
Por su parte, la mujer capta la atención de su gestualidad en las caderas realizando movimientos de cintura. Esta zona del cuerpo ha sido identif cada por un gran número de civilizaciones y épocas como símbolo de vida, de fertilidad y por consiguiente, de feminidad.

La búsqueda de nuevos identif cadores con respecto al género de cada cual parece evidente. La voluntad de igualdad se ve paradójicamente en contradicción por la necesidad de reaf rmar una identidad, comenzando por la identidad sexual.

\section{Conclusiones}

El papel social del hombre y de la mujer tiende a la unicidad. En el baile famenco, esto se ref eja porque se van borrando progresivamente los rasgos característicos de la plástica coreográ $\mathrm{f}$ ca propios a cada uno. Las técnicas corporales hasta ahora propias a cada género, se ponen al alcance de ambos en las escuelas y en los conservatorios así como el uso de esta técnica durante la composición coreográf ca. Los elementos que pertenecían en el pasado especí f camente al hombre o a la mujer, se utilizan hoy en día por ambos géneros pero de distinto modo. Rasgos característicos aparecen y desaparecen con el tiempo. A pesar de las técnicas de aprendizaje de la danza puestas al alcance de ambos géneros que los tienden a uniformizarla tendencia es la de encontrar nuevos rasgos diferenciadores. Los mayores elementos de diferenciación hasta hace unos cincuenta años eran, por el lado femenino, la utilización casi exclusiva del braceo, y por el lado masculino, la preferencia por el zapateado, condicionando así las estructuras de los bailes. Estos elementos se han vuelto comunes y un nuevo rasgo distintivo ha aparecido: la acentuación de los movimientos de cadera en el baile de mujer.

De este modo, a pesar de que el aprendizaje del bailef amenco sea común, se hace un uso diferente de la manera de utilizar la técnica adquirida. En el baile f amenco, la identidad femenina y la identidad masculina conservan y respetan un carácter biológico natural.

\section{Bibliografía}

Fernando el de Triana 1935: Arte y artistas flamencos, Madrid, Ed. Clan.

Guilcher, Y. 1988: Toute forme de danse n'est pas possible à n'importe quelle époque. La recherche en danse, 4, 29-36.

Hanna, J. L. 1987: Dance, sex and gender. Signs of identity, dominance, defiance and desire. Chicago, The University of Chicago Press.

Ordóñez Flores, E. 2001: La danse flamenca: études de son rythme et de son esthétique. Paris, Thèse, Université Paris IV-Sorbonne.

Ordóñez Flores, E. 2008: Dance improvisation rules and practise in the cuadro flamenco. The world of music, 50, (1), 33-47.

Rice, T. 2003: Time, place and metaphor in musical experience and ethnography. Ethnomusicology , 47, (2), 151-179. 


\section{Notas}

1. La invención de la máquina de vapor d\$att en 1762, marca el comienzo de la Revolución Industrial en Inglaterra. Este período es uno de los que más cambios ha conocido el mundo del trabajo. Poco a poco, el trabajo mecánico va a sustituir al manual por toda Europa y más adelante en el mundo entero.

2. En este mismo periodo es también cuando los primeros testimonios sobre ef amenco nos llegan, identif cándose y designándose con este mismo término «f amenco ».

3. Los términos de cantaor y cantaora están aceptados por la Real Academia de la Lengua Española y se aplica al cantante def amenco. Son los que se usarán a lo lago de todo este estudio.

4. Los términos de bailaor y bailaora están aceptados por la Real Academia de la Lengua Española y se aplica al bailarín de f amenco. Son los que se usarán a lo largo de todo este estudio cuando se trate de designar un bailef amenco en su forme de tablao y no de ballet.

5. Cuando se trata de famenco, el uso del término bailarín, está vinculado a la forma de ballet. Con este término se designan a los bailarines en una obra de ballet aunque esta sea f amenca ya que implica que tengan una formación completa según los planes de estudio de la carrera de Danza española impartida en los Conservatorios españoles. Esto es, de ballet, baile f amenco, danza estilizada y escuela bolera.

6. Se entiende por palo cada una de las piezas musicales del repertorio $f$ amenco.

7. Farruca, del árabe faruq, signif ca valiente.

8. Caracoles: palo caracterizado por un compás de doce tiempos de la familia de las alegrías.

9. Abanico de gran tamaño propio del baile f amenco.

10. Aquí se re f ere al palo del zapateado. Pieza del repertorio famenco caracterizado por un compás 6/8. Su mayor rasgo identitario es que la coreografía está compuesta mayoritariamente por zapateados, golpes de zapato sobre la tarima del escenario. Este palo no se canta, solo se baila o se interpreta a la guitarra.

11. Aquí se ref ere a la percusión realizada a través de golpes de zapato sobre la tarima del escenario.

12. Martinete: palo caracterizado por un compás o ciclo rítmico de cinco tiempos fuertes. El cante no lleva acompañamiento de guitarra. Sin embargo, se suele marcar el compás por el golpe de un martillo sobre un yunque o golpeando dos piezas metálicas.

13. Seguiriya : palo caracterizado por un compás o ciclo rítmico de cinco tiempos fuertes. Contrariamente al martinete, el cante lleva acompañamiento de guitarra.

14. Id.

15. El cuadro f amenco se compone de al menos un cantaor , un guitarrista y un bailaor . Eventualmente, puede haber percusionistas de cajón y palmeros, personas encargadas de hacer pasmas de apoyo. Los miembros se colocan en semicírculo al fondo del escenario delimitando de este modo el espacio escénico del bailaor.

16. Elemento estructural del baile zapateado.

17. Los f nales en el baile $f$ amenco suelen componerse mayoritariamente de un movimiento acelerado para salir del escenario.

18. Carmen Amaya (1913-1963)

19. Silencio: parte estructural del baile por alegrías en la cual se pone el acento en el braceo y movimientos lentos permitiendo lucirse a las bailaoras. 
20. Alegrías : palo caracterizado por un compás de doce tiempos de carácter alegre.

21. Mirabrás : palo caracterizado por un compás de doce tiempos de la familia de las alegrías.

22. Romera : palo caracterizado por un compás de doce tiempos de la familia de las alegrías.

23. Caña : palo caracterizado por un compás de doce tiempos de la familia de las soleares.

24. Elemento de articulación en el bailf amenco que consiste en zapatear muy marcadamente una orden de cambio estructural.

25. Bulería: palo caracterizado por un compás de doce tiempos muy complejo. Es de carácter simpático, alegre, pícaro y burlesco.

26. Contrariamente a la pirueta clásica en la que todo el bloque corporal gira excepto la cabeza que queda de frente la última y llega al punto de llegada la primera, la vuelta f amenca se caracteriza por que cada segmento del cuerpo va llegando a su vez al punto de llegada, empezando por los pies y acabando por la cabeza, dando así una sensación de movimiento en espiral. 